\title{
O Planejamento do Turismo como Disciplina: estudo de caso com os cursos superiores de turismo no Paraná, Brasil
}

\author{
Tourism Planning as a Discipline: a case study on undergraduate courses in Paraná, \\ Brazil
}

\section{La Planificación Turística como Asignatura: un caso de estudio con los programas superiores de turismo de Paraná, Brasil}

\author{
Carlos Eduardo Silveira ${ }^{1}$ \\ José Manoel Gonçalves Gândara²
}

\begin{abstract}
Resumo
O Estudo de caso que segue é resultado da participação dos autores e posterior análise do relatório da Reunião do Fórum dos Coordenadores dos Cursos Superiores de Turismo e/ou Hotelaria, ocorrido em Curitiba em 2008, com a participação não só de coordenadores, mas também de professores de planejamento turístico de várias regiões do Estado do Paraná. O objetivo do encontro foi discutir, em forma de oficina participativa, a disciplina de Planejamento Turístico nos cursos superiores de turismo no Paraná, incluindo a metodologia empregada, inserção no curso e relação com outras áreas do saber. Por tratar-se de tema pouco explorado pela literatura específica, o caso estudado organiza informações que, ainda que já fossem conhecidas empiricamente, raramente são tratadas na bibliografia da área de Planejamento Turístico. As principais conclusões apontam para o caráter teórico-prático da disciplina, a aproximação com as políticas públicas do turismo e a amplitude de áreas relacionadas com planejamento turístico. $\mathrm{O}$ artigo abre discussão para temas compatíveis ou para análise em outros âmbitos geográficos para comparação.
\end{abstract}

Palavras-chave: turismo; ensino superior; planejamento turístico; fórum de coordenadores.

\section{Abstract}

The following case study is the result of the authors' participation and later analysis of the Tourism Higher Education Course Coordinator Forum report that took place in Curitiba in

\footnotetext{
1 Bacharel e Especialista em Turismo e Hotelaria pela UNIVALI, Mestre em Turismo em Países em Desenvolvimento pela University of Strathclyde, Doutor em Gestão e Desenvolvimento do Turismo Sustentável pela Universidade de Málaga, professor e pesquisador da Faculdade Interdisciplinar em Humanidades da Universidade Federal dos Vales do Jequitinhonha e Mucuri FIH/UFVJM. E-mail: caesilveira@gmail.com.

${ }^{2}$ Bacharel em Turismo pela Universidade Federal do Paraná, Mestre em Gestão do Turismo pela SSCTS de Milão, Doutor em Turismo e Desenvolvimento Sustentável pela Universidade de Las Palmas de Gran Canaria, Professor e Pesquisador do Departamento de Turismo e do Mestrado e Doutorado em Geografia da Universidade Federal do Paraná. E-mail: jmggandara@yahoo.com.br.
} 
2008 attended not only by course coordinators but also tourism planning lecturers from a number of regions of Paraná State. The meeting aimed at discussing, using a participative method, tourism planning discipline in Parana's tourism higher education courses. This included its insertion in the course, methods applied and interactions with other fields of knowledge. Due to the fact that Tourism Planning teaching is not a very frequent theme on specific literature, the case study is useful to organise information which might even be empirically known, but is rarely part of tourism planning bibliography. The main conclusions were that the discipline tends to have both theoretical and hands-on approach, as well as close relations with policy-making, and a wide variety of areas that contribute to tourism planning class contents. The article opens discussions on using the same methodology to either assess other disciplines or tourism planning teaching in different places.

Keywords: tourism; higher education; tourism planning; coordinators forum.

\section{Resumen}

El siguiente caso de estudio es resultado de la participación de los autores y posterior análisis del informe de la Reunión del Foro de los Coordinadores de los Programas Superiores de Turismo y/u Hostelería, que ocurrió en Curitiba en 2008, con la participación no solo de coordinadores, pero también de profesores de planificación turística de varias regiones del Estado de Paraná. El objetivo del encuentro fue discutir, en forma de taller participativo, la asignatura de Planificación Turística en los programas superiores de turismo en Paraná, incluyendo la metodología empleada, inserción en el programa y relación con otras áreas del saber. Por tratarse de tema poco tratado en la literatura especifica, el caso estudiado organiza informaciones que, a pesar de conocidas empíricamente, raramente son tratadas en la literatura del área de Planificación Turística. Las principales conclusiones apuntan para el carácter teórico-práctico de la asignatura, el acercamiento con las políticas públicas del turismo y la amplitud de áreas relacionadas con planificación turística. El artículo abre discusión para temas compatibles o para análisis en otros ámbitos geográficos para comparación.

Palabras clave: turismo; educación superior; planificación turística; foro de coordinadores.

\section{Introdução}

O caráter operacional e tecnicista que acompanha a formação superior em turismo no Brasil, desde sua origem, aliado à acelerada expansão que os cursos sofreram especialmente nos anos 1990, criaram um ambiente infrutífero para a sustentabilidade do ensino superior do turismo no Brasil. Muito desse cenário se deve a decisões políticas, sejam de caráter educacional, sejam de caráter turístico, já que formação superior em Turismo e mais especialmente a área 
de Planejamento Turístico, possuem fortes vínculos com as políticas públicas (Beni, 2006). Enquanto disciplina, Ruschmann e Widmer (2001, p. 72) mencionam que

Em cursos de graduação a disciplina intitulada Planejamento Turístico tem como objetivo capacitar alunos para a utilização adequada de técnicas e instrumentos pertinentes ao planejamento, considerando todos os fatores intervenientes na elaboração de planos de desenvolvimento turístico, em seus diferentes níveis.

Se considerarmos que uma das principais influências ligadas ao planejamento é a formulação das políticas públicas, percebemos a importância dessa aproximação.

De fato Hall (2001) já menciona a estreita ligação entre políticas e planejamento colocando-os lado a lado em termos de importância para o desenvolvimento adequado de um destino. Beni (2001, p. 177) menciona que a

A política de turismo é a espinha dorsal do 'formular' (planejamento), do 'pensar' (plano), do 'fazer' (projetos, programas), do 'executar' (preservação, conservação, utilização e ressignificação dos patrimônios natural e cultural e sua sustentabilidade) do 'reprogramar' (estratégia) e do 'fomentar' (investimentos e vendas) o desenvolvimento turístico de um país ou de uma região e seus produtos finais.

Dencker (2004, p. 2) ainda observa que

O ensino do planejamento nos cursos de turismo possui um perfil teórico/prático voltado para o treinamento em técnicas de planejamento adotadas pelos organismos oficiais e em modelos desenvolvidos por organizações internacionais adaptados ao contexto brasileiro.

Contudo, em função da ênfase que se dá à atividade do planejamento turístico, muitas vezes em detrimento de seu ensino, o estudo de caso que segue se apresenta como um subsídio para a compreensão do ensino dessa área, em especial, e sua ligação com o desenvolvimento da atividade por parte dos egressos. 
Há uma quantidade considerável de obras relacionadas ao ensino do Turismo, inclusive no Brasil, o que se reflete até mesmo nos eventos da área que costumam possuir Grupos de Apresentação de Trabalhos dedicados ao ensino e à epistemologia do Turismo. Interessantemente, porém, ainda que o Planejamento Turístico seja uma das áreas mais consolidadas no ensino do turismo, há muito pouco escrito especificamente sobre o ensino dessa área em disciplinas de cursos superiores em turismo, e menos ainda a respeito da inserção profissional do Turismólogo como Planejador de Turismo.

Por esse motivo, optou-se por analisar a realidade vivida no caso da disciplina de Planejamento, mais especificamente no Paraná, por meio do estudo de caso baseado no relatório de uma oficina com professores do ensino superior desse Estado.

\section{Metodologia}

Historicamente um caso é visto entre os acadêmicos positivistas como uma ferramenta de pouco valor entre as metodologias existentes. Brotherton (1999) discorda dos positivistas e toma a perspectiva interpretativa da família da fenomenologia argumentando o valor de obter entendimento novo sobre a dimensão teórica por meio do processo indutivo, o qual oferece uma generalização teórica que vai além do simples caso documental.

Justificar um caso documental não é uma tarefa fácil, já que este é concebido como uma fonte de manipulação, ou uma fonte de informação especifica. Por outro lado, Hartley (1994, pp. 208-209) sugere que um caso documental

Consiste numa pesquisa detalhada, obtida de maneira longitudinal sobre um período determinado de tempo, sobre distintos entes e/ou grupos dentro de uma mesma organização; com intenção de observar e realizar análise sobre o contexto e os processos nos quais participa a fenomenologia.

Da mesma forma, Yin (1994, p.13) aprofunda esta definição, denotando que o estudo de caso documental é uma consulta empírica que busca pesquisar um fenômeno contemporâneo com base num contexto real especialmente quando os limites entre o fenômeno e o contexto não são evidentes entre si. 
O que oferece um caso documental é uma cobertura contextual sobre as condições do fenômeno estudado. Um dos propósitos que assinala Yin (1993) é que a observação de fundo 'particular' de natureza processual tende a envolver-se em situações de um interesse particular sobre um fenômeno num tempo determinado.

Não obstante, por tratar-se de um caso específico dentro de um contexto geográfico delimitado, ou seja, o Estado de Paraná, lançou-se mão de ferramentas de pesquisa qualitativas para estudar o tema da educação superior em turismo com base na experiência e nos relatos de professores da área, incluindo os autores, como se apresenta a seguir.

\section{A Oficina do Fórum de Coordenadores de Cursos de Turismo e/ou Hotelaria do Paraná}

Criado em 2003, o Fórum de Coordenadores de Turismo do Paraná, como é conhecido, é uma entidade oficial, cujo objetivo é debater os princípios e as práticas do ensino do turismo, além de representar oficialmente os cursos de Turismo e/ou Hotelaria desse estado (PAIXÃO e GANDARA, 2004). Em reunião realizada paralelamente ao IX Encontro Estadual de Secretários, Dirigentes e Técnicos Municipais de Turismo e a IV Mostra das Regiões Turísticas do Paraná, realizados de 8 a 12 de abril de 2008, no Centro de Convenções de Curitiba e no Estação Embratel Convention Center, respectivamente, foi realizado um trabalho na forma de oficina que teve como objetivo aproximar metodologias de ensino de Planejamento Turístico e as Políticas Públicas de Turismo destinadas a esta área no Paraná.

Nesse evento os trabalhos seguiram os princípios do Enfoque Participativo que "enfatiza o desenvolvimento de processos de transformação e de mudança, principalmente no aspecto comportamental dos indivíduos e, em conseqüência, nas suas instituições” (CORDIOLI, 2001, p.31). Essa metodologia enfatiza o intercâmbio de experiências e conhecimentos, tendo como ferramentas metodológicas a visualização, a problematização, documentação, trabalho em grupos, sessões plenárias, contando com o apoio de um moderador (José Gabriel Pesce Jr.) que segundo Cordioli (op cit, p.57) "é o elemento de equilíbrio, catalisador para as diversas idéias que aparecerão decorrentes do processo grupal”. No caso em questão a metodologia participativa foi conduzida de forma muito similar a um grupo focal. 
A reunião contou com a presença de 13 professores de Planejamento Turístico ou áreas afins de diversas Instituições de Ensino Superior do Estado, contando inclusive, com membros do próprio Governo Estadual, já que uma das professoras da UFPR dirige o setor de Planejamento Turístico da Secretaria de Turismo do Estado. Além dos professores de planejamento participaram 8 coordenadores de curso, incluindo o Presidente e o Vice do Fórum de Coordenadores, professores Paixão e Gandara, que no início da ofícina fizeram uma breve apresentação sobre a importância do ensino do planejamento turístico e sua relação com as políticas públicas. Os coordenadores, ainda que também fossem professores, não eram necessariamente da área de planejamento, mas possuíam a visão ampla dos cursos e compreendiam a importância da área para a formação de turismólogos.

Houve grande representatividade regional de Instituições de Ensino Superior - IES do Estado, com participantes vindos das cidades de Apucarana, Campo Mourão, Cascavel, Curitiba, Foz do Iguaçu, Irati, Maringá, Ponta Grossa, São Miguel do Iguaçu e Telêmaco Borba, que representam quase todas as regiões onde há cursos de turismo no Paraná, como pode ser percebido no quadro a seguir:

Quadro 1 - IESs Participantes de Oficina

Centro Universitário Curitiba - UNICURITIBA

Centro Universitário Maringá - CESUMAR

Faculdade de Telêmaco Borba - FATEB

Faculdade Internacional de Curitiba - FACINTER

Faculdades Integradas do Brasil - UNIBRASIL

Faculdade de Apucarana - FAP

Faculdade Estadual de Ciências e Letras de Campo Mourão FECILCAM

Faculdade de Ensino Superior de São Miguel do Iguaçu UNIGUAÇÚ- FAESI

Pontifícia Universidade Católica do Paraná - PUCPR

Universidade Estadual de Ponta Grossa - UEPG

Universidade Estadual do Centro-Oeste - UNICENTRO

Universidade Estadual do Oeste do Paraná - UNIOESTE

Universidade Federal do Paraná - UFPR

Universidade Paranaense - UNIPAR

Universidade Positivo - UP

Universidade Tuiuti do Paraná - UTP

Fonte: Elaboração própria a partir de FCCSTH (2008). 
Buscando atender o objetivo de aproximar as metodologias de ensino de Planejamento Turístico e as Políticas Públicas de Turismo destinadas a esta área no Paraná, os participantes foram inicialmente divididos em quatro grupos, aleatoriamente, sendo que cada grupo trabalhou com duas perguntas, uma geral e outra específica, sempre discutindo e apresentando suas compreensões sobre relação entre planejamento turístico e políticas públicas de turismo, além de refletir sobre papéis (cursos de turismo e bacharéis) no planejamento turístico bem como, nivelar informações. $\mathrm{Na}$ fase seguinte os participantes apresentaram as principais ideias resultantes dos debates em grupo e em conjunto debateram e construíram os resultados apresentados nas tabelas que seguem, que por terem sido logrados por consenso, representam as opiniões do grupo como um todo.

Tabela 1 - O papel dos cursos superiores de turismo segundo os professores do Paraná

\begin{tabular}{|c|c|}
\hline Papel & Descricão \\
\hline Ensino & $\begin{array}{l}\text { - } \quad \text { Unir a teoria à prática } \\
\text { - } \quad \text { Ensinar e praticar ferramentas } \\
\text { - } \quad \text { Base metodológica } \\
\text { - } \quad \text { Formação de Planejadores reflexivos e responsáveis } \\
\text { - Formação de Planejadores que conheçam as realidades } \\
\text { locais e regionais } \\
\text { - Discutir a realidade turística } \\
\text { - } \quad \text { Estimular o pensamento crítico } \\
\text { - Gerar conhecimentos (teoria e prática com discussão e } \\
\text { aperfeiçoamento) }\end{array}$ \\
\hline Pesquisa & $\begin{array}{ll}\text { - } & \text { Aplicabilidade } \\
\text { - } & \text { Identificação de necessidades de pesquisa } \\
\text { - } & \text { Pesquisar modelos e realidades }\end{array}$ \\
\hline Extensão & $\begin{array}{l}\text { - Desenvolver atividades de extensão } \\
\text { - Ajudar no Planejamento de Destinos e/ou Produtos } \\
\text { Turísticos } \\
\text { - Treinamento } \\
\text { - Participação efetiva na governança local e regional } \\
\text { - Conscientização de todos os atores envolvidos } \\
\text { (público/privado) } \\
\text { - Articulação }\end{array}$ \\
\hline Mercado & - Foco no mercado \\
\hline
\end{tabular}


Percebe-se uma ênfase no papel de integração dos cursos superiores com a realidade local e regional através de ações que os articulem como atores.

Uma das dificuldades identificadas, ainda que o Fórum pregue a integração e compartilhamento de informações (PAIXÃO e GANDARA, 2004), foi o alto grau de concorrência entre os cursos, intensificado pela crise dos cursos de turismo (BOLSON, 2004; SANTOS Filho, 2004; GONTIJO, 2004). Por muitos anos a interação entre a Universidade e o meio onde se localizava foi vista como uma importante função da academia, sendo estimulada a inclusão de estágios e outras atividades programadas que davam um caráter extensionista e participativo aos cursos de turismo. Porém, com a mudança nas Leis de Diretrizes e Bases da Educação (BRASIL, 1996) e a conseqüente abertura de mercado para o ensino superior, a livre concorrência propiciou a criação de incontáveis instituições de ensino superior e essa sobre-oferta não foi acompanhada de um aumento das necessidades da sociedade em relação às atividades desenvolvidas pelas IESs, e, na prática, houve uma diminuição da representatividade de cada curso no turismo local, restringindo o espaço de participação dessas IESs na sua interação com a sociedade (BERBERI et al, 2006).

Com relação ao que se ministra nas disciplinas de Planejamento e áreas afins, os professores indicaram inicialmente um rol de disciplinas relacionadas a Planejamento Turístico existentes nos cursos paranaenses, totalizando 13 disciplinas com denominações distintas, algumas muito semelhantes e outras mais diversificadas como se mostra no quadro abaixo:

Quadro 2 - Nomes das disciplinas

\begin{tabular}{|c|c|}
\hline & $\begin{array}{l}\text { Desenvolvimento Turístico } \\
\text { Ordenamento Turístico Territorial } \\
\text { Organização do Turismo } \\
\text { Planejamento do Turismo } \\
\text { Planejamento e Organização do Turismo } \\
\text { Planejamento Turístico em Áreas Naturais } \\
\text { Planejamento Turístico em Áreas Urbanas } \\
\text { Planejamento, Organização e Sistemas de Turismo } \\
\text { Políticas Públicas de Turismo } \\
\text { Projetos e Consultoria } \\
\text { Projetos Turísticos } \\
\text { Projetos Turísticos Locais } \\
\text { Sistemas Turísticos }\end{array}$ \\
\hline
\end{tabular}

Fonte: Elaboração própria a partir de FCCSTH (2008). 
A descrição dos conteúdos de cada disciplina seguiu o contexto geral, sem diferenciação por nomes ou áreas de disciplinas, incluindo tanto áreas de conhecimento quanto temas específicos tratados ao longo das disciplinas. Para fins de comparação e análise, o quadro apresentado abaixo inclui a visão de Ruschmann e Widmer (2001) acerca dos conteúdos que, segundo as autoras, devem ser incluídos em uma disciplina de Planejamento Turístico:

Quadro 3 - Comparativo de conteúdos das disciplinas da área de planejamento: comparação do proposto pelos professores de cursos do Paraná e Ruschmann e Widmer (2001)

\begin{tabular}{|c|c|}
\hline $\begin{array}{c}\text { Oficina do Fórum de Coordenadores de } \\
\text { Turismo do Paraná }\end{array}$ & $\begin{array}{l}\text { Proposta de Ruschmann e Widmer para a } \\
\text { Disciplina de Planejamento turístico }\end{array}$ \\
\hline $\begin{array}{ll}\text { - } & \text { Conceituação (terminologias, } \\
\text { tipologias, dimensiones, etc.) } \\
\text { - } \quad \text { Sistemas e Sistur } \\
\text { - } \quad \text { Etapas do Planejamento } \\
\text { - } \quad \text { Políticas Públicas (municipal, } \\
\text { regional, estadual, nacional) } \\
\text { - } \quad \text { Planejamento turístico em Áreas } \\
\text { Naturais e Urbanas } \\
\text { - } \quad \text { Planejamento Urbano } \\
\text { - } \quad \text { Marketing } \\
\text { - } \quad \text { Planejamento Participativo } \\
\text { - } \quad \text { Espaço turístico } \\
\text { - } \quad \text { Projetos e colaboração com a } \\
\text { comunidade } \\
\text { - } \quad \text { Parecer técnico } \\
\text { - } \quad \text { Criação de produtos } \\
\text { - } \quad \text { Métodos e técnicas de sensibilizacão } \\
\text { - } \quad \text { Organizações turísticas } \\
\text { - } \quad \text { Fluxos, Gastos } \\
\text { - } \quad \text { Plano Diretor } \\
\text { - } \quad \text { Metodologia de Planejamento } \\
\text { - } \quad \text { Captação de recursos e fontes de } \\
\text { financiamento } \\
\text { - } \quad \text { Turismo sustentável } \\
\text { - } \quad \text { Planejamento estratégico } \\
\text { - } \quad \text { Processo de gestão } \\
\text { - } \quad \text { Planejamento regional } \\
\text { - } \quad \text { Estudos de oferta e demanda turística } \\
\text { - } \quad \text { Hierarquização dos atrativos } \\
\text { - } \quad \text { Instrumentos / ferramentas de controle } \\
\text { e avaliação }\end{array}$ & $\begin{array}{l}\text { • Importância, necessidade e conceitos de } \\
\text { Planejamento } \\
\text { • Objetivos, formas, níveis e instrumentos } \\
\text { de Planejamento } \\
\text { • Breve histórico do Planejamento em } \\
\text { Brasil e no mundo } \\
\text { • Relação entre Planejamento e turismo } \\
\text { • } \quad \text { Análise de políticas e planos de } \\
\text { desenvolvimento } \\
\text { • Modelos e métodos de planejamento } \\
\text { turístico } \\
\text { • Relações da atividade turística bem } \\
\text { sucedida com as necessidades de preservação } \\
\text { ambiental e sociocultural } \\
\text { • } \quad \text { Fases de elaboração de um plano de } \\
\text { desenvolvimento turístico de um núcleo } \\
\text { receptor } \quad \text { Elaboração de inventário da } \\
\quad \text { o } \quad \text { oferta turística } \\
\circ \quad \text { Análise mercadológica do núcleo } \\
\text { receptor (análise da oferta e da demanda } \\
\text { - real e potencial - turísticas e de os } \\
\text { pontos fortes e fracos de os núcleos } \\
\text { competentes) } \\
\circ \quad \text { Elaboração do diagnóstico e do } \\
\text { prognóstico turísticos } \\
\circ \quad \text { Definição de objetivos, metas e } \\
\text { estratégias } \\
\circ \quad \text { Avaliação e estudos de } \\
\text { viabilidade do plano elaborado } \\
\circ \quad \text { Implantação e acompanhamento } \\
\text { do plano }\end{array}$ \\
\hline
\end{tabular}

Fonte: Elaboração própria a partir de FCCSTH (2008) e Ruschmann e Widmer (2001 apud Almeida, 2006). 
Percebe-se, em termos de conteúdo, uma grande proximidade com o proposto em forma de texto por Ruschmann e Widmer em 2001 e posteriormente apresentado de forma organizada em tópicos por Almeida em 2006, e os conteúdos das disciplinas apresentados pelos professores participantes da oficina. As atividades acadêmicas, ainda segundo os professores, devem ser tanto de cunho teórico quanto prático, o que vai ao encontro do que foi levantado por Silveira et al (2008), em pesquisa realizada com professores de Curitiba. O resultado dessa discussão entre os participantes da oficina sobre as metodologias de ensino empregadas nas disciplinas é apresentado na tabela abaixo:

Tabela 2 - Metodologia de ensino empregada

\begin{tabular}{ll}
\hline Metodologia & Atividades \\
\hline Teoria & $\bullet \quad$ Pesquisa bibliográfica e documental \\
& $\bullet \quad$ Estudos de Caso (incluindo criação) \\
& $\bullet \quad$ Análise e comparações de os diferentes \\
Prática & modelos existentes \\
& $\bullet \quad$ Pesquisas de campo \\
& $\bullet \quad$ Visitas técnicas \\
\hline
\end{tabular}

Fonte: Elaboração própria a partir de FCCSTH (2008).

Os professores concordam, entretanto, que a dimensão prática deve ter enfoque técnico e acadêmico, com finalidade de aprendizagem. Almeida $(2006$, p.86) corrobora mencionando que "o plano de desenvolvimento turístico não é o objetivo único do planejamento, mas um meio para alcançar outros objetivos". O mesmo acontece com o Plano em relação ao ensino desta disciplina: esta atividade, extremamente rica e importante, deve ser encarada como um meio para a aprendizagem, e não como um fim em si mesma.

Um dos grupos teve como tarefa levantar os autores mais utilizados pelos professores e o resultado vai ao encontro, em grande medida, das outras pesquisas que vêm sendo conduzidas pelos autores deste trabalho acerca do tema.

Apresenta-se o quadro-resumo a seguir: 
Quadro 4 - Autores e outras referências usados na disciplina

\begin{tabular}{|c|c|}
\hline Autores & Outros Materiais \\
\hline Chris Cooper & \\
Cláudia Magalhães & \\
Débora Braga & \\
Dóris Ruschmann & \\
Josep Ivars & Annals of Tourism Research (periódico) \\
Josep Valls & Estudios e Perspectivas en Turismo \\
(periódico) \\
Jost Krippendorf & Gestão Municipal de Turismo (Manual \\
Margarita Barretto & SETU) \\
Maria Angela Bissoli & Plano Estadual de Turismo \\
Mário Beni & Plano Nacional de Turismo \\
Mário Petrocchi & Publicações da OMT \\
Michael Hall & Revistas virtuais \\
Miguel Acerenza & Turismo em Análise (periódico) \\
Milton Santos & Turismo: Visão e Ação (periódico) \\
Philip Kotler & \\
Reinaldo Dias & \\
Roberto Boullón & \\
Sérgio Molina & \\
Willian Theobald & \\
\hline
\end{tabular}

Fonte: Elaboração própria a partir de FCCSTH (2008).

É importante destacar dois pontos a respeito dos autores e do material mencionados. Em primeiro lugar os professores participaram da oficina sem seu material de trabalho usual, ou seja, tanto os autores quanto o material mencionado foram top of mind, mas, ainda assim alguns dos mais importantes autores e periódicos nacionais e internacionais foram mencionados. Chama muito à atenção o fato de documentos governamentais (estaduais e nacionais) serem mencionados como fontes de consulta para as disciplinas, por serem materiais que não são exclusivamente de planejamento turístico, senão que, de áreas correlatas, denotando a proximidade existente entre o que se entende por planejamento e por políticas públicas no turismo. Com relação aos autores, percebe-se claramente a interdiscipliaridade da área e o tráfego por outras disciplinas quando menciona-se nomes da Geografia (como Milton Santos), do Marketing (Philip Kotler), das áreas amplas de turismo (Beni; Barretto; Cooper, etc.) e das áreas específicas de política e planejamento (Hall; Ruschmann; etc.). 
Tais características denotam a intenção de formar um profissional com visão ampla e abrangente, como se destaca na última etapa da oficina, com respeito ao papel do Bacharel em Turismo no planejamento de destinos e produtos turísticos.

Quadro 5 - O papel do bacharel em turismo no Planejamento de produtos e destinos turísticos

\begin{tabular}{|c|}
\hline Articulação entre o público e o privado \\
Articulação com outras áreas \\
Articular / trabalhar a importância do espaço \\
Articular a ocupação dos espaços \\
Colaborar ou cooperar no planejamento de destinos e produtos \\
Coordenar e gerir o planejamento de destinos e produtos \\
Elaborar, desenvolver, executar e avaliar planos, políticas e produtos \\
Empreender - criar e gerir produtos turísticos
\end{tabular}

Fonte: Elaboração própria a partir de FCCSTH (2008).

A análise referente à questão anterior aplica-se a esta também já que os aspectos apresentados no quadro anterior sobre o papel do bacharel em turismo no Planejamento são reflexo de discussões restritas ao ambiente e às circunstâncias da oficina.

Entretanto, se pouco foi escrito sobre o planejamento turístico como disciplina ou sobre seu ensino e aprendizagem, menos ainda há sobre a atuação de bacharéis em turismo nessa área. Sabe-se que no âmbito geográfico de Curitiba, os egressos de cursos de Turismo que atuam com Planejamento Turístico (exclusivamente ou em conjunto com outras áreas) representam 10\% dos turismólogos formados na cidade segundo Medaglia e Silveira (2009), num estudo que teve como foco a atuação de bacharéis em turismo com planejadores, incluindo suas expectativas enquanto eram estudantes comparadas com sua atividade atual. Percebe-se que os esforços que são impingidos pelos professores durante a formação profissional, não resultam num direcionamento eficaz em termos de mercado no que diz respeito à inserção profissional de Turismólogos na área de Planejamento Turístico. Seria muito importante buscar identificar se isto é reflexo da formação realizada ou da falta de mercado de trabalho na área de planejamento turístico. 


\section{Considerações Finais}

Ante à carência de referencial teórico concernente ao ensino e à atuação profissional em planejamento Turístico, o estudo de caso apresentado serve para elucidar algumas questões tratadas de forma mais ampla na bibliografia existente a respeito da formação em turismo.

Em primeiro lugar se percebe a clara intenção dos professores em aliar a teoria à prática, com conteúdos que sejam aplicáveis no mercado. Sabe-se, entretanto, que o mercado profissional de planejadores é restrito e que apenas uma pequena parcela de egressos atuará na área de planejamento turístico. Tal atuação profissional não é garantida nem mesmo pela ampla combinação de ensino, pesquisa e extensão focada em planejamento turístico, conforme apresentado no estudo de caso. Fica claro, entretanto, que nos cursos superiores de turismo é dada grande importância a formação e atuação na área de planejamento turístico.

É notório também, no caso da disciplina de planejamento turístico, a amplitude de áreas vinculadas ao planejamento turístico e que há uma intenção de aproximação com as políticas públicas estaduais e federais mostrada pelos professores em suas colocações na oficina, denotando a aproximação entre as áreas de planejamento e políticas em turismo, ainda que o caráter público não seja exclusivo na área e que muitos conteúdos da área de gestão tenham sido apresentados pelos participantes. Essa diversidade de áreas reflete também na variada lista de autores apresentada, o que reitera a amplitude da área e sua interdependência com outras áreas do saber.

Por fim, ainda que um estudo de caso não seja eminentemente conclusivo, pode-se perceber pelo que foi apresentado que existe dentro do Paraná uma amplitude considerável de áreas e conteúdos vinculados ao ensino do planejamento turístico, e que mesmo uma área tradicional com essa não possui um eixo temático fixo. Tal constatação abre possibilidades de novas discussões sobre a área, seja em outros âmbitos geográficos, a fim de gerar comparações, seja com outras disciplinas a fim de refinar as discussões tão presentes sobre a criação de um corpo de estudos próprio do turismo. Se por um lado tem-se percebido uma retração em termos de mercado de trabalho para turismólogos, por outro percebe-se um nível crescente de aprofundamento das discussões teóricas que devem caminhar, se não para a definição de uma ciência, ao menos para uma consolidação da área de estudos delimitada. 


\section{Referências}

ALMEIDA, M V. O Ensino de planejamento turístico no Brasil: reflexões e recomendações para a prática pedagógica. In: RUSCHMANN, D e SOLHA, K T. Planejamento Turístico. Barueri: Manole, 2006.

BENI, M C. Política e planejamento de turismo no Brasil. São Paulo: Aleph, 2006.

BENI, M C. A política do turismo. In: TRIGO, L. Turismo: como aprender, como ensinar. São Paulo: Senac, 2001.

BERBERI, A; SILVEIRA, C E; PAIXÃO, D ; COBOS, V. (2006). Ensino superior de turismo no Brasil e a necessidade de alinhamento com uma política nacional de turismo. I Encontro Estadual de Pesquisadores em Hotelaria e Turismo. Campo Mourão: 2006.

BOLSON, J. A crise nos cursos superiores de turismo: de quem é a culpa? In: Revista Turismo, 2004. Disponível em: $<$ http://www.revistaturismo.com.br>. Acesso em: 07 jan. 2009.

BRASIL. LEI n 9.394, DE 20 DE DEZEMBRO DE 1996. Lei de Diretrizes e Bases da Educação. Estabelece as diretrizes e bases da educação nacional.

BROTHERTON, B. The handbook of contemporary hospitality management research. Sussex: John Wiley \& Sons, West, 1999.

CORDIOLI, S. Enfoque participativo: um processo de mudança. Conceitos, instrumentos e aplicação prática. Porto Alegre: Genesis, 2001.

DENCKER, A. Planejamento turístico: propostas inovadoras de ensino. VI Congresso Mercocidades. Porto Alegre: 2004.

FCCSTH. Relatório da reunião do Fórum dos Coordenadores dos Cursos Superiores de Turismo elou Hotelaria. IX Encontro Estadual de Secretários, Dirigentes e Técnicos Municipais de Turismo. Curitiba, 2008.

GONTIJO, J. Mudança urgente nos cursos de turismo. In: Estudos Turísticos, 2004. Disponível em: $<$ http://www.etur.com.br>. Acesso em: 20 jan. 2009.

HALL, C M. Planejamento turístico: políticas, processos e relacionamentos. São Paulo: Contexto, 2001.

HARTLEY, J. Designing instructional text. Londes: Kogan Page, 1994.

MEDAGLIA, J; SILVEIRA, C E. Reflexões sobre a atuação profissional dos turismólogos e o planejamento do turismo: pesquisa com os egressos dos cursos de Turismo de Curitiba. Turismo \& Sociedade, vol.3, n.2, p.123-146, 2009.

PAIXÃO, D; GANDARA, J. A relação entre formação de recursos humanos e o desenvolvimento sustentável do turismo: uma análise da educação turística na cidade de Curitiba. Ciência e Opinião, vol.1, n. 2/4, jul. 2003/dez 2004.

RUSCHMANN, D; WIDMER, G. Planejamento turístico. In: ANSARAH, M. G. R. Turismo. Como aprender, como ensinar. Volume II. São Paulo: Senac, 2001.

SANTOS FILHO, J. O Curso universitário de turismo sofre as conseqüências da política neoliberal. Revista Espaço Acadêmico. n. 42, novembro 2004, Ano IV, 2004. Disponível em: $<$ http://www.espacoacademico.com.br>. Acesso em: 12 jan. 2010. 
SILVEIRA, C. E.; GÂNDARA, J. M. G.; MEDAGLIA, J. A disciplina de Planejamento Turístico no Ensino Superior de Turismo: das influências aos novos desafios. Revista Brasileira de Pesquisa em Turismo. v. 2, n. 1, p. 113-133, mar. 2008.

YIN, R. Case study research: design and methods. Beverly Hills: Sage Publishing, 1994.

YIN, R. Applications of case study research. Beverly Hills: Sage Publishing, 1993.

Recebido em: 27/01/2011

Aprovado em: 31/03/2011 (1 ${ }^{\mathrm{a}}$ versão) 09/11/2011 (2 $2^{\mathrm{a}}$ versão) 